\title{
Studies on the mechanisms underlying $\beta$-adrenoceptor- mediated relaxation of rat abdominal aorta
}

\author{
Mayumi Matsushita ${ }^{1}$, Yoshio TANAKA ${ }^{1}$ and Katsuo KoIKE ${ }^{1}$ \\ ${ }^{1}$ Department of Chemical Pharmacology, Toho University School of Pharmaceutical \\ Sciences, 2-2-1 Miyama, Funabashi-City, Chiba 274-8510, Japan
}

Received August 7, 2006; Accepted December 7, 2006

\begin{abstract}
Mechanisms underlying $\beta$-adrenoceptor ( $\beta$-AR)-mediated vascular relaxation were studied in the isolated rat abdominal aorta. In the endothelium-denuded helical preparations, a non-selective $\beta$-AR agonist isoprenaline elicited a concentrationdependent relaxation. In the absence of $\beta$-AR antagonists, isoprenaline-induced relaxation was not practically affected by an adenylyl cyclase inhibitor SQ 22,536 (300 $\mu \mathrm{M})$, but was strongly diminished by high- $\mathrm{KCl}(80 \mathrm{mM})$. Isoprenaline-induced relaxation in the presence of SQ 22,536 was significantly diminished by iberiotoxin (IbTx, $0.1 \mu \mathrm{M}$ ), but was not affected by 4 -aminopyridine (4-AP, $3 \mathrm{mM}$ ). Isoprenaline-induced relaxation was not also affected by SQ 22,536 $(300 \mu \mathrm{M})$ even in the presence of CGP20712A (a $\beta_{1}$ selective antagonist) and ICI-118,551 (a $\beta_{2}$-selective antagonist) $(0.1 \mu \mathrm{M}$ for each), but was strongly diminished by high- $\mathrm{KCl}$. By contrast, SQ 22,536-resistant, isoprenalineinduced relaxation in the presence of CGP20712A plus ICI-118,551 was not affected by IbTx $(0.1 \mu \mathrm{M})$, but was inhibited significantly by 4 -AP $(3 \mathrm{mM})$. These results suggest that in rat abdominal aortic smooth muscle: 1 ) both $\beta_{1}-/ \beta_{2}$-AR- and $\beta_{3}$-AR-mediated relaxations substantially involve cAMP-independent mechanisms; 2) $\beta_{1}-/ \beta_{2}$-AR-mediated, cAMP-independent relaxant mechanisms are partly attributed to the large-conductance, $\mathrm{Ca}^{2+}$-sensitive $\mathrm{K}^{+}$(MaxiK, BK) channel whereas $\beta_{3}$-AR-mediated relaxant mechanisms are attributed to $\mathrm{K}_{\mathrm{v}}$ channel.
\end{abstract}

Key words: $\beta$-adrenoceptor $\left(\beta\right.$-AR), cAMP, isoprenaline, MaxiK channel, $\mathrm{K}_{\mathrm{v}}$ channel

\section{Introduction}

We have previously shown that relaxant response to a non-selective $\beta$-adrenoceptor ( $\beta$-AR) agonist isoprenaline (ISO) is mediated through propranolol-sensitive and -insensitive $\beta$-ARs in rat abdominal aorta (Matsushita et al., 2003). Propranolol-sensitive $\beta$-ARs may involve a mixed population of $\beta_{1}$-AR and $\beta_{2}$-AR whereas propranolol-insensitive $\beta$-ARs contain $\beta_{3}$-AR that is sensitive to bupranolol (Matsushita et al., 2003). In any cases, isoprenaline-induced relaxation

Correspondence to: Yoshio Tanaka, Ph.D., Department of Chemical Pharmacology, Toho University

School of Pharmaceutical Sciences, Miyama 2-2-1, Funabashi-City, Chiba 274-8510, Japan

Phone: +81-47-472-1435 Fax: +81-47-472-1448 e-mail: yotanaka@phar.toho-u.ac.jp 
of this vascular muscle should involve cAMP-dependent mechanisms since any of these $\beta$-AR subtypes are coupled to adenylyl cyclase via $\mathrm{G}_{\mathrm{s}}$ protein (Tanaka et al., 2005). On the other hand, $\beta$-AR-mediated smooth muscle relaxations are not exclusively triggered through cAMPdependent mechanisms but also involve cAMP-independent mechanisms (Ferro, 2006; Horinouchi and Koike, 2002; Koike et al., 2004; Tanaka et al., 2003; Tanaka et al., 2005). However, little information is available so far on the possible contribution of cAMP-independent mechanisms to $\beta$-AR-mediated relaxation of vascular smooth muscle. In the present study, we show that cAMP-independent mechanisms significantly trigger both propranolol-sensitive $\left(\beta_{1^{-}} /\right.$ $\beta_{2}$-ARs-mediated) and -insensitive ( $\beta_{3}$-ARs-mediated) relaxations in rat abdominal aorta. We also indicate that $\beta$-AR-mediated, cAMP-independent mechanisms are attributed in part to the activation of $\mathrm{K}^{+}$channels although the key $\mathrm{K}^{+}$channel subclass differs depending on the $\beta$-AR subtypes.

\section{Methods}

\section{Animals}

Male Wistar rats weighing 150-200 g (Murai Experimental Animals, Saitama, Japan) were used in the present study. Rats were housed under laboratory standard conditions on a $12-\mathrm{h}$ light/dark cycle (lights on 8:00 a.m.; lights off 8:00 p.m.) in the rooms in which temperature $\left(20-22^{\circ} \mathrm{C}\right)$ and relative air humidity $(50 \pm 5 \%)$ were strictly regulated. Food and water were available ad libitum to all animals. This study was conducted in accordance with the Guideline for the Care and Use of Laboratory Animals adopted by the Committee on the Care and Use of Laboratory Animals of Toho University School of Pharmaceutical Sciences (accredited by The Ministry of Education, Culture, Sports, Science, and Technology (MEXT), Japan), and the experimental protocol of the present study was approved by the Institutional Animal Care and Use Committee.

\section{Preparation of abdominal aorta}

Rats were stunned and killed by cervical dislocation and exsanguinated. A section of the abdominal aorta between diaphragm and a bifurcation of iliac arteries was removed and placed in Krebs solution (mM: NaCl, 118; KCl, 4.75; $\mathrm{CaCl}_{2}, 2.54 ; \mathrm{MgSO}_{4}, 1.20 ; \mathrm{KH}_{2} \mathrm{PO}_{4}, 1.19 ; \mathrm{NaHCO}_{3}$, 25.0 and $\mathrm{D}-(+)$-glucose, 11.0 ), which was gassed with $95 \% \mathrm{O}_{2}-5 \% \mathrm{CO}_{2}$ mixture. The abdominal aorta was cleaned of loosely adhering fat and connective tissue under a dissecting microscope. The aorta was then helically cut into sections approximately $15 \mathrm{~mm}$ in length and $1 \mathrm{~mm}$ in width. Usually, two helical strip preparations were obtained from each aorta. The endothelium was removed by gentle rubbing of the intimal surface with a moistened cotton swab.

\section{Measurement of tension changes}

The helical strips of abdominal aorta were mounted under the optimal resting tension of 1.0 $\mathrm{g}$ in a 20-ml glass organ bath containing Krebs solution (Matsushita et al., 2003). Tension changes of the muscle preparation were isometrically recorded with a force-displacement transducer (TB-612T, Nihon Kohden, Tokyo, Japan) connected to a carrier amplifier (AP-621G, 
Nihon Kohden). The aortic preparations were equilibrated for 60-90 min prior contractions by successive 2-3 times applications of phenylephrine $(0.3 \mu \mathrm{M})$ with a 30 -min washout interval. In the last time of phenylephrine-induced contraction, the lack of relaxation to acetylcholine (ACh, $10 \mu \mathrm{M}$ ) was confirmed to assure the absence of functional endothelial cells. Isoprenalineinduced relaxation experiments were started after a further 30-min equilibration period. Krebs solution was continuously gassed with $95 \% \mathrm{O}_{2}-5 \% \mathrm{CO}_{2}$, and kept at $36.5 \pm 0.5^{\circ} \mathrm{C}(\mathrm{pH}=7.4)$. Indomethacin ( $3 \mu \mathrm{M}$, a cyclooxygenase inhibitor) and L-ascorbic acid (10 $\mu \mathrm{M}$, an antioxidant for isoprenaline) were present in the bath solution throughout the experiments.

Examination of the effects of adenylyl cyclase and $K^{+}$channel inhibitors on the relaxations to isoprenaline and CGP12177A

After the equilibration period, each preparation was initially contracted with phenylephrine $(0.3 \mu \mathrm{M})$. A sustained plateau phase was observed 30-40 min after its administration. Then, concentration-response curves to isoprenaline or CGP12177A were constructed. This procedure was repeated two times and the second response was regarded as control. In some experiments, control response was obtained in the presence of SQ 22,536 (an adenylyl cyclase inhibitor, $300 \mu \mathrm{M}$ ), CGP20712A (a $\beta_{1}$-AR selective antagonist) plus ICI-118,551 (a $\beta_{2}$-AR selective antagonist) $(0.1 \mu \mathrm{M}$ for each), SQ 22,536 and CGP20712A plus ICI-118,551. The effects of SQ $22,536, \mathrm{~K}^{+}$channel inhibitors and high- $\mathrm{KCl}(80 \mathrm{mM})$ on the responses to isoprenaline and CGP12177A were examined in the separate preparations from the same rat.

When the effects of high- $\mathrm{KCl}$ on the relaxations to isoprenaline and CGP12177A were examined, relaxant responses to these $\beta$-AR agonists against phenylephrine $(0.3 \mu \mathrm{M})$-induced contraction were compared with those against high- $\mathrm{KCl}(80 \mathrm{mM})$-induced contraction. Any $\beta$ $\mathrm{AR}$ antagonists and $\mathrm{K}^{+}$channel inhibitors used in the present study did not affect phenylephrineinduced contraction. In addition, phenylephrine-induced contraction and high-KCl-induced contraction were almost practically the same level.

\section{Drugs}

The following drugs were used in the present study: (-)-isoprenaline hydrochloride, (-)phenylephrine hydrochloride, 4-aminopyridine (4-AP), iberiotoxin (IbTx), glibenclamide, apamin, indomethacin, L-ascorbic acid (Sigma-Aldrich, St. Louis, MO, U.S.A.); CGP20712A (( \pm )2-hydroxy-5-[2-[[2-hydroxy-3-[4-[1-methyl-4-(trifluoromethyl)-1H-imidazol-2-yl]phenoxy]propyl] amino] ethoxy]-benzamide methanesulfonate), ICI-118,551 (( \pm )-1-[2,3-(dihydro-7-methyl-1Hinden-4-yl)oxy]-3-[(1-methylethyl)amino]-2-butanol hydrochloride), CGP12177A (( \pm$)$ CGP12177A) (( \pm )-[4-[3-[(1,1-dimethylethyl) amino]-2-hydroxypropoxy]-1,3-dihydro-2Hbenzimidazol-2-one] hydrochloride), SQ 22,536 (9-(tetrahydro-2-furanyl)-9H-purin-6-amine) (Research Biochemicals International, Natick, MA, U.S.A.); acetylcholine chloride (Daiichi Pharmaceutical, Tokyo, Japan) and ( \pm )-bupranolol hydrochloride (Kaken Pharmaceutical, Tokyo, Japan). The other chemicals used were of analytical grade.

CGP20712A was dissolved in dimethylsulfoxide (DMSO) to form a stock solution of $20 \mathrm{mM}$, and further diluted in distilled water. Indomethacin was dissolved in $2 \% \mathrm{Na}_{2} \mathrm{CO}_{3}$ to form a stock solution of $20 \mathrm{mM}$, and further diluted in distilled water. Final DMSO and $\mathrm{Na}_{2} \mathrm{CO}_{3}$ 


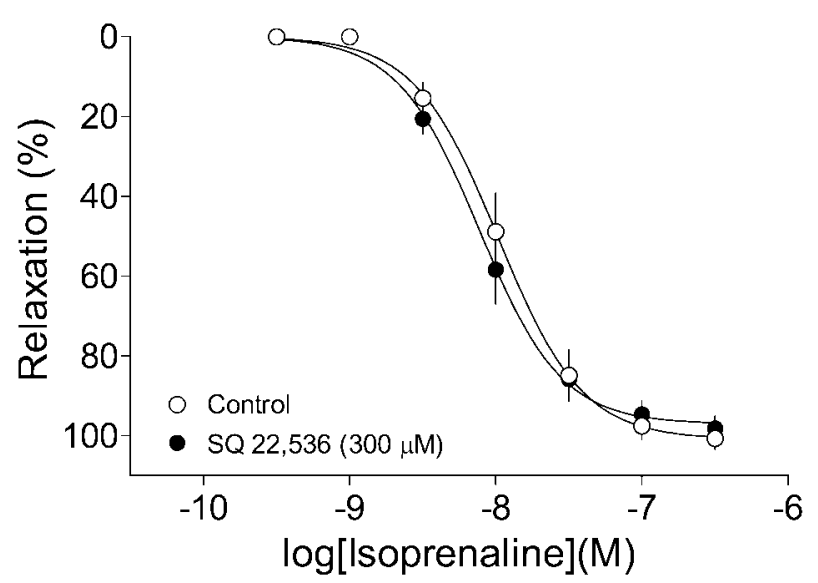

Fig. 1. Effects of SQ 22,536 on the relaxant response of rat abdominal aorta to isoprenaline in the absence of $\beta$-AR antagonists. Data are means \pm S.E.M. of 3 experiments for each group.

concentrations in the bath solution did not affect muscle responses (data not shown). All other drugs were dissolved in and diluted with distilled water. Drug concentrations were expressed as mol/L (M) order.

\section{Analysis and statistics}

The relaxant percentage was calculated by considering the muscle tension level obtained just before administration of $\beta$-AR agonists (isoprenaline and CGP12177A) as $0 \%$ relaxation, and the full recovery to the basal tension before application of phenylephrine $(0.3 \mu \mathrm{M})$ or high- $\mathrm{KCl}$ $(80 \mathrm{mM})$ as $100 \%$ relaxation. Data were plotted as a function of the concentrations $\beta$-AR agonists. Data are presented as means \pm S.E.M. of $n$ numbers of experiments. The significance of the difference between mean values was evaluated with GraphPad Prism ${ }^{\mathrm{TM}}$ (version 4.00, GraphPad Software, Inc., San Diego, CA, U.S.A.) by paired or unpaired $t$-test, unpaired $t$-test with Welch's correction if necessary. A $P$ value less than 0.05 was considered statistically significant.

\section{Results}

Isoprenaline elicited a concentration-dependent relaxation in the abdominal aortic preparations precontracted with phenylephrine $(0.3 \mu \mathrm{M})$. Figure 1 shows the effects of SQ 22,536 on the isoprenaline-induced relaxation in the absence of any $\beta$-AR antagonists. As shown clearly, isoprenaline-induced relaxation was not affected at all by SQ 22,536 (300 $\mu \mathrm{M})$.

Similarly, isoprenaline-induced relaxation was not dramatically diminished by SQ 22,536 in the presence of CGP20712A (a $\beta_{1}$-selective antagonist) plus ICI-118,551 (a $\beta_{2}$-selective antagonist) $(0.1 \mu \mathrm{M}$ for each), although inhibitory effects of SQ 22,536 was significant at some concentrations (Fig. 2A). As expected, relaxation to CGP12177A (a nonconventional $\beta_{3}$-AR agonist) in the presence of CGP20712A plus ICI-118,551 was not also affected by SQ 22,536 (Fig. 2B). 

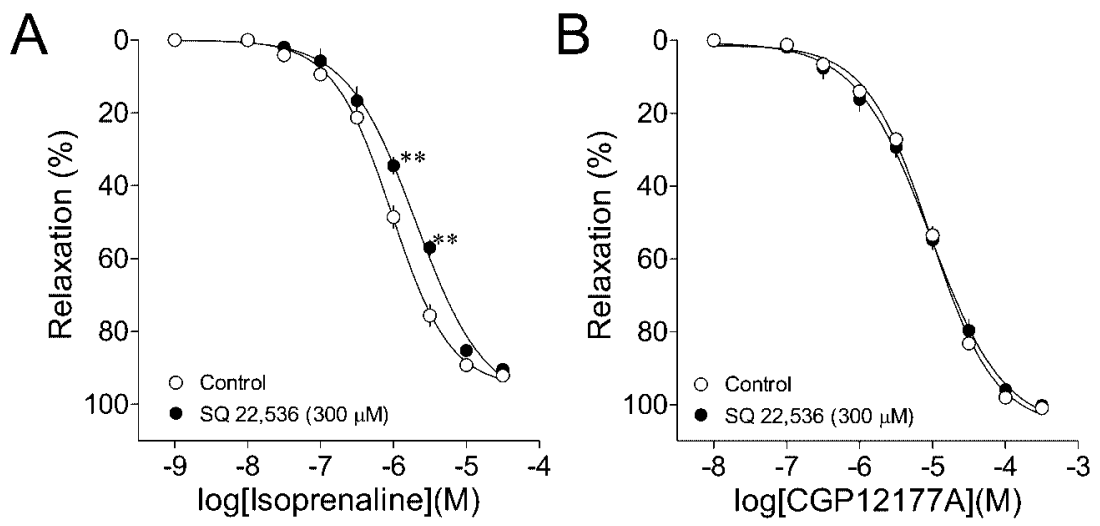

Fig. 2. Effects of SQ 22,536 on the relaxation of rat abdominal aorta to isoprenaline (A) and CGP12177A (B) in the presence of $\beta$-AR antagonists. $\beta$-AR antagonists were: CGP20712A as a $\beta_{1}$-AR selective antagonist plus ICI-118,551 as a $\beta_{2}$-AR antagonist $(0.1$ $\mu \mathrm{M}$ for each). Data are means \pm S.E.M. of 8 experiments for each group. ${ }^{*} * P<0.01$ : significant differences between two groups.
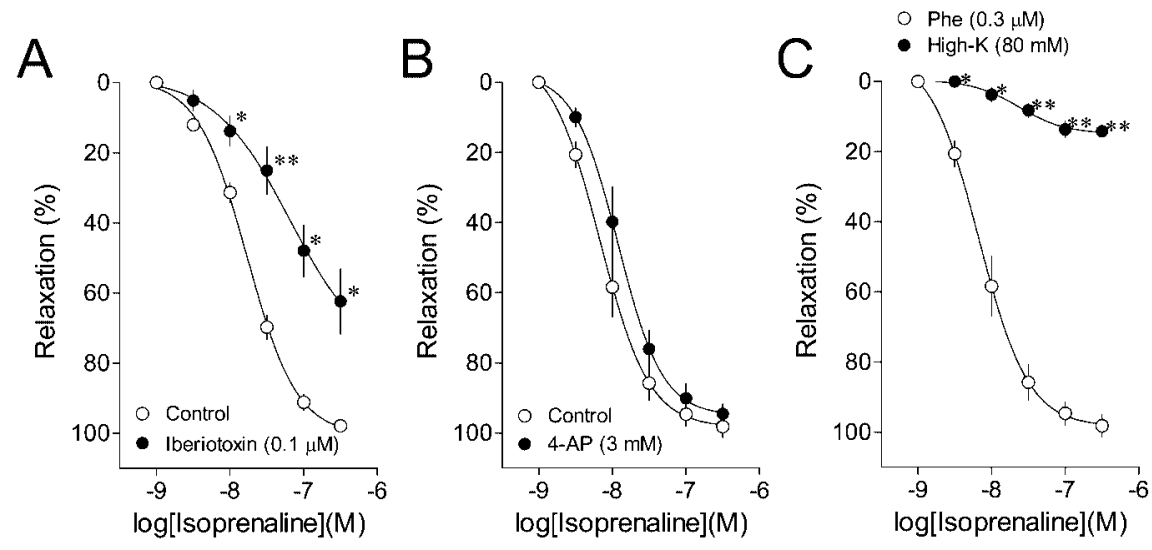

Fig. 3. Effects of IbTx (A), 4-AP (B) and high- $\mathrm{KCl}(\mathrm{C})$ on the SQ 22,536-insensitive relaxation of rat abdominal aorta to isoprenaline in the absence of $\beta$-AR antagonists. The concentrations of $\mathrm{K}^{+}$channel inhibitors and high- $\mathrm{KCl}$ are: $0.1 \mu \mathrm{M}$ for IbTx (A); $3 \mathrm{mM}$ for 4-AP (B); $80 \mathrm{mM}$ for high- $\mathrm{KCl}(\mathrm{C})$. SQ 22,536 $(300 \mu \mathrm{M})$ was present for all. Data are means \pm S.E.M. of $3-4$ experiments for each group. $* P<0.05 ; * * P<0.01$ : significant differences between two groups.

In the next series of experiments, effects of iberiotoxin (IbTx) and 4-aminopyridine (4-AP) were examined on SQ 22,536-insensitive relaxation to isoprenaline (Figs. 3 and 4) and CGP12177A (Fig. 5). In the absence of any $\beta$ AR antagonists, isoprenaline-induced, SQ 22,536resistant relaxation was significantly diminished by $\mathrm{IbTx}(0.1 \mu \mathrm{M})$ (Fig. 3A) whereas it was not affected by 4-AP (3 mM) (Fig. 3B). On the other hand, in the combined presence of CGP20712A plus ICI-118,551 $(0.1 \mu \mathrm{M}$ for each) and SQ 22,536 (300 $\mu \mathrm{M})$, relaxations to isoprenaline (Fig. 4A) and CGP12177A (Fig. 5A) were not affected practically by IbTx $(0.1 \mu \mathrm{M})$. By contrast, the SQ 22,536-insensitive relaxations to isoprenaline (Fig. 4B) and CGP12177A (Fig. 5B) were 

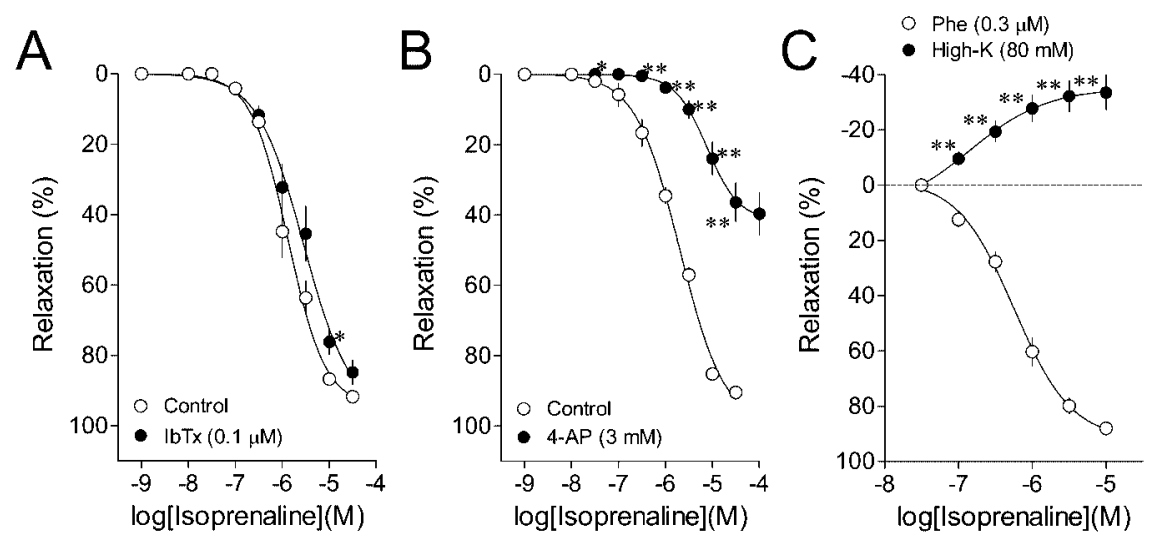

Fig. 4. Effects of IbTx (A), 4-AP (B) and high- $\mathrm{KCl}(\mathrm{C})$ on the SQ 22,536-insensitive relaxation of rat abdominal aorta to isoprenaline in the presence of $\beta$-AR antagonists (CGP20712A plus ICI-118,551, $0.1 \mu \mathrm{M}$ for each). The concentrations of $\mathrm{K}^{+}$channel inhibitors and high- $\mathrm{KCl}$ are: $0.1 \mu \mathrm{M}$ for IbTx (A); $3 \mathrm{mM}$ for 4-AP (B); $80 \mathrm{mM}$ for high- $\mathrm{KCl}$ (C). SQ $22,536(300 \mu \mathrm{M})$ was present for all. Data are means \pm S.E.M. of $4-8$ experiments for each group. $* P<0.05 ; * * P<0.01$ : significant differences between two groups.
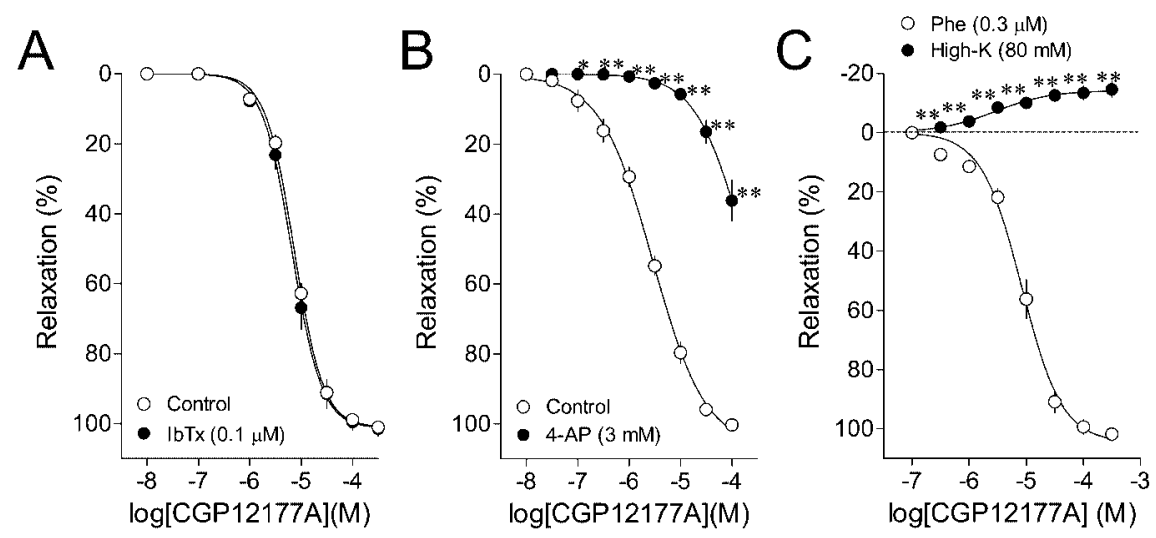

Fig. 5. Effects of $\mathrm{IbTx}(\mathrm{A}), 4-\mathrm{AP}(\mathrm{B})$ and high- $\mathrm{KCl}(\mathrm{C})$ on the relaxation of rat abdominal aorta to CGP12177A in the presence of $\beta$-AR antagonists (CGP20712A plus ICI$118,551,0.1 \mu \mathrm{M}$ for each). The concentrations of $\mathrm{K}^{+}$channel inhibitors and high-KCl are: $0.1 \mu \mathrm{M}$ for IbTx (A); $3 \mathrm{mM}$ for 4-AP (B); $80 \mathrm{mM}$ for high-KCl (C). SQ 22,536 (300 $\mu \mathrm{M})$ was present for all. Data are means \pm S.E.M. of 4-8 experiments for each group. $* P<0.05 ; * * P<0.01$ : significant differences between two groups.

significantly diminished by 4-AP (3 mM). In all cases, SQ 22,536-insensitive relaxations to isoprenaline and CGP12177A were strongly diminished by high- $\mathrm{KCl}(80 \mathrm{mM})$ (Figs. 3-5C). SQ 22,536-insensitive relaxations to isoprenaline and CGP12177A in the presence of CGP20712A plus ICI-118,551 were not affected significantly by glibenclamide $(10 \mu \mathrm{M})$, apamin $(1 \mu \mathrm{M})$ and $\mathrm{Ba}^{2+}(10 \mu \mathrm{M})$ (data not shown). 


\section{Discussion}

$\beta$-ARs that mediate smooth muscle relaxation induced by isoprenaline are divided into two groups depending on the features of sensitivity to propranolol. One group shows propranololsensitive characteristics and includes $\beta_{1}$-AR and $\beta_{2}$-AR. Another group exhibits propranololinsensitive characteristics, the representative of which is $\beta_{3}$-AR (Arch and Kaumann, 1993; Koike and Takayanagi, 1998; Nagatomo and Koike, 2000; Tanaka et al., 2005). This classification well applies to the $\beta$-ARs in rat abdominal aorta (Matsushita et al., 2003). However, in the case of this vascular smooth muscle, $\beta$-AR subtypes mediating propranolol-sensitive relaxation still remain unclear, and thus, we describe these $\beta$-ARs as $\beta_{1}-/ \beta_{2}$-ARs. On the other hand, propranolol-insensitive relaxation of this muscle is mediated in part through $\beta_{3}$-AR since this relaxation is competitively antagonized by bupranolol that exhibits a $\beta_{3}$-AR antagonistic characteristic (Matsushita et al., 2003). Consequently, this paper regarded the $\beta$-AR mediating propranolol-insensitive relaxation as $\beta_{3}$-AR.

First of all, we studied the effects of an adenylyl cyclase inhibitor SQ 22,536 (Turcato and Clapp, 1999; Yamaki et al., 2001) on the relaxant response to isoprenaline, and found that isoprenaline-induced relaxation was not practically diminished by SQ 22,536 in the absence of any $\beta$-AR antagonists. The relaxation to isoprenaline was not also affected by SQ 22,536 under the condition that both $\beta_{1}$-AR and $\beta_{2}$-AR were inhibited by CGP20712A plus ICI-118,551. Similarly, the relaxation to a $\beta_{3}$-AR selective agonist CGP12177A was not affected by SQ 22,536. These findings strongly suggest that mechanisms unrelated to tissue cAMP elevation (cAMPindependent mechanisms) contribute to aortic relaxations mediated through $\beta_{1}-/ \beta_{2}$-ARs and $\beta_{3}$ AR. This view supports strongly our previous findings that cAMP-independent mechanisms are significant in $\beta_{2}$-AR-mediated tracheal relaxation (Koike et al., 2004; Tanaka et al., 2003) and $\beta_{3^{-}}$ AR-mediated gastrointestinal relaxation (Horinouchi and Koike, 2002; Horinouchi et al., 2003). Consequently, contribution of cAMP-independent mechanisms to $\beta$-AR-mediated relaxation is not exclusive to non-vascular smooth muscle tissues but is also significant to vascular smooth muscle tissues.

In the next series of experiments, we examined the possible mechanisms responsible for $\beta$ AR-mediated, cAMP-independent relaxation focusing on the roles of MaxiK channel and $\mathrm{K}_{\mathrm{v}}$ channel, both of which mediate in part cAMP-independent relaxations in trachea (for $\beta_{2}$-AR) (Tanaka et al., 2003) and gastrointestinal tracts (for $\beta_{3}$-AR) (Horinouchi et al., 2003). Our results show that isoprenaline-induced relaxation in the absence of $\beta$-AR antagonists was inhibited potently by IbTx, whereas it was not diminished by 4-AP ( $3 \mathrm{mM})$. On the other hand, the isoprenaline-induced relaxation in the presence of $\beta_{1}$-AR and $\beta_{2}$-AR antagonists was not affected by IbTx but was significantly diminished by $3 \mathrm{mM}$ 4-AP. In addition, CGP12177Ainduced relaxation in the presence of these $\beta$ AR antagonists was significantly attenuated by 3 $\mathrm{mM}$ 4-AP being not affected by IbTx. These findings basically support our previous findings on $\beta_{2}$-AR and $\beta_{3}$-AR-mediated relaxations (Horinouchi et al., 2003; Tanaka et al., 2003), indicating $\beta$ AR subtype-specific coupling with the particular $\mathrm{K}^{+}$channel partner. Substantial participation of $\mathrm{K}^{+}$channels to $\beta$-AR-mediated, cAMP-independent relaxation is endorsed by the strong attenuation of the relaxant responses by high- $\mathrm{KCl}$ (Figs. 3-5C). 
Isoprenaline-induced relaxation in the absence of $\beta$-AR antagonists was not apparently inhibited by 4 -AP $(3 \mathrm{mM})$ although this inhibitor significantly attenuated the relaxation in the presence of $\beta$-AR antagonists. One of the explanations accounting for this result would be the difference of the expression densities of each $\beta$-AR subtype; the expression level of $\beta_{3}$-AR may be lower than that of $\beta_{1}-/ \beta_{2}$-ARs and thus inhibitory effects of 4-AP on isoprenaline-induced relaxation was not apparently detected in the absence of $\beta$-AR antagonists. This view can be supported by more than 10-fold decrease of $\mathrm{p} D_{2}$ value of isoprenaline in the presence of $\beta$-AR antagonists (Matsushita et al., 2003). Another factor would be the difference of MaxiK and $\mathrm{K}_{\mathrm{v}}$ channel densities. These possibilities should be substantiated by the measurement of plasma membrane expression levels for each $\beta$-AR and $\mathrm{K}^{+}$channel subtype.

When $\beta_{1}-/ \beta_{2}$-ARs are blocked, isoprenaline produced a contraction instead of relaxation in the preparation pre-contracted with high-KCl (Fig. 4C). This phenomenon was also observed when CGP12177A was used as a relaxant agonist (Fig. 5C). These contractile effects of isoprenaline and CGP12177A might be ascribed to the direct actions of these $\beta$-agonists on vascular smooth muscle $\alpha\left(\alpha_{1}\right)$-adrenoceptors (Akimoto et al., 2003).

In conclusion, the present study provided for the first time pharmacological evidence showing that $\beta$-AR-mediated relaxation of rat abdominal aorta involves significantly cAMPindependent mechanisms. The present study also indicated that cAMP-independent functional coupling between $\beta$-ARs and $\mathrm{K}^{+}$channels is governed in a $\beta$-AR subtype-specific manner: MaxiK channel dominates $\beta_{1}-/ \beta_{2}$-AR-medaited relaxation whereas $\mathrm{K}_{\mathrm{v}}$ channel primarily contributes to $\beta_{3}$-AR-mediated relaxant response. Detailed molecular mechanisms by which stimulation of each $\beta$-AR subtype leads to activation of the corresponding $\mathrm{K}^{+}$channel subclass and their physiological significances should be established in feature.

\section{Acknowledgements}

This study was supported in part by Grant-in-Aids for Scientific Research (C) (18590157 for YT; 18590242 for KK) from Japan Society for the Promotion of Science (JSPS), and the Science Research Promotion Fund from the Promotion and Mutual Aid Corporation for Private Schools of Japan (KK).

\section{References}

Akimoto, Y., Horinouchi, T., Shibano, M., Matsushita, M., Yamashita, Y., Okamoto, T., Yamaki, F., Tanaka, Y. and Koike, K. (2002). Nitric oxide (NO) primarily accounts for endotheliumdependent component of $\beta$-adrenoceptor-activated smooth muscle relaxation of mouse aorta in response to isoprenaline. J. Smooth Muscle Res. 38: 87-99.

Arch, J.R.S. and Kaumann, A.J. (1993). $\beta_{3}$ and atypical $\beta$-adrenoceptors. Med. Res. Rev. 13: 663-729.

Ferro, A. (2006). $\beta$-Adrenoceptors and potassium channels. Naunyn-Schmiedeberg's Arch. Pharmacol. 373: $183-185$.

Horinouchi, T. and Koike, K. (2002). Cyclic AMP-independent relaxation mediated by $\beta_{3}$-adrenoceptors on guinea pig gastrointestine. Eur. J. Pharmacol. 442: 137-146.

Horinouchi, T., Tanaka, Y. and Koike, K. (2003). Evidence for the primary role for 4-aminopyridine- 
sensitive $\mathrm{K}_{\mathrm{v}}$ channels in $\beta_{3}$-adrenoceptor-mediated, cyclic AMP-independent relaxations of guinea-pig gastrointestinal smooth muscles. Naunyn-Schmiedeberg's Arch. Pharmacol. 367: 193203.

Koike, K. and Takayanagi, I. (1998). $\beta_{3}$-Adrenoceptor mechanisms in guinea-pig taenia caecum. Life Sci. 62: 1503-1507.

Koike, K., Yamashita, Y., Horinouchi, T., Yamaki, F. and Tanaka, Y. (2004). cAMP-independent mechanism is significantly involved in $\beta_{2}$-adrenoceptor-mediated tracheal relaxation. Eur. J. Pharmacol. 492: 65-70.

Matsushita, M., Horinouchi, T., Tanaka, Y., Tsuru, H. and Koike, K. (2003). Characterization of $\beta_{3^{-}}$ adrenoceptor-mediated relaxation in rat abdominal aorta smooth muscle. Eur. J. Pharmacol. 482: 235-244.

Nagatomo, T. and Koike, K. (2000). Recent advances in structure, binding sites with ligands and pharmacological function of $\beta$-adrenoceptors obtained by molecular biology and molecular modeling. Life Sci. 66: 2419-2426.

Tanaka, Y., Horinouchi, T. and Koike, K. (2005). New insights into $\beta$-adrenoceptors in smooth muscle: distribution of receptor subtypes and molecular mechanisms triggering muscle relaxation. Clin. Exp. Pharmacol. Physiol. 32: 503-514.

Tanaka, Y., Yamashita, Y., Yamaki, F., Horinouchi, T., Shigenobu, K. and Koike, K. (2003). MaxiK channel mediates $\beta_{2}$-adrenoceptor-activated relaxation to isoprenaline through cAMPdependent and -independent mechanisms in guinea-pig tracheal smooth muscle. J. Smooth Muscle Res. 39: 205-219.

Turcato, S. and Clapp, L.H. (1999). Effects of the adenylyl cyclase inhibitor SQ22536 on iloprost-induced vasorelaxation and cyclic AMP elevation in isolated guinea-pig aorta. Br. J. Pharmacol. 126: 845-847.

Yamaki, F., Kaga, M., Horinouchi, T., Tanaka, H., Koike, K., Shigenobu, K., Toro, L. and Tanaka, Y. (2001). MaxiK channel-mediated relaxation of guinea-pig aorta following stimulation of IP receptor with beraprost via cyclic AMP-dependent and -independent mechanisms. NaunynSchmiedeberg's Arch. Pharmacol. 364: 538-550. 